\title{
Que faremos nós com o que daqui para trás ficou?
}

\section{LEONOR MADUREIRA}

Título: Traces of Antigone. Concepção e direcção artística: Elli Papakonstantinou. Texto: Christina Ouzounidis. Tradução (grego): Margarita Mellberg. Tradução (inglês): Gemma Carbone, Elli Papakonstantinou, Eirini Dermitzaki. Interpretação: Gemma Hansson Carbone, Katerina Papachristou, Nalyssa Green, Serafita Grigoriadou, Sophia Manoli, Valia Papachristou. Assessoria arte visual e vídeo-poemas: Mary Zigouri. Música original e interpretação: Nalyssa Green (voz, piano), Katerina Papachristou (voz, piano, baixo). Direcção de movimento: Valia Papachristou. Fotografia: FLP Athens, Sophia Manoli. Produção: ODC Ensemble. Co-produção: Naprawsky, Teater Galeasen, Scenkonstbiennalen, Teater Tribunalen. Local e data de estreia: Livestream na Plataforma Zoom, 18 de Maio de 2020 .

HÉMON Nenhum Estado é de um homem só! CREONTE Então o Estado não é de quem manda?

sófocles, Antígona

Num momento em que, olhando para lá das nossas janelas para a rua vazia, procuramos respostas para o amanhã, num momento em que olhando para os responsáveis que se sentam nas várias cadeiras de poder, para os protestos que brotam do silêncio a que foram votados os problemas estruturais ainda inerentes ao mundo que habitamos, num momento em que procuramos as respostas para um futuro que não entrevemos ainda, tudo se avizinha incerto. Face à realidade política que observamos, retorno frequentemente à passagem de Antígona citada acima.

As perguntas, as decisivas e as insignificantes, acumulam-se. E, se procuramos respostas, Traces of Antigone não no-las quer dar. Nem sobre $o$ papel do poder político, nem sobre a democracia - neste momento em que de todas as direções vemos a crescente adesão à extrema-direita -, nem sobre a violência de género, nem sobre o futuro da cultura na era pós-pandémica. Entramos num território dialético, de desconstrução, de questionamento, de incerteza. E talvez seja isto que precisamos para 


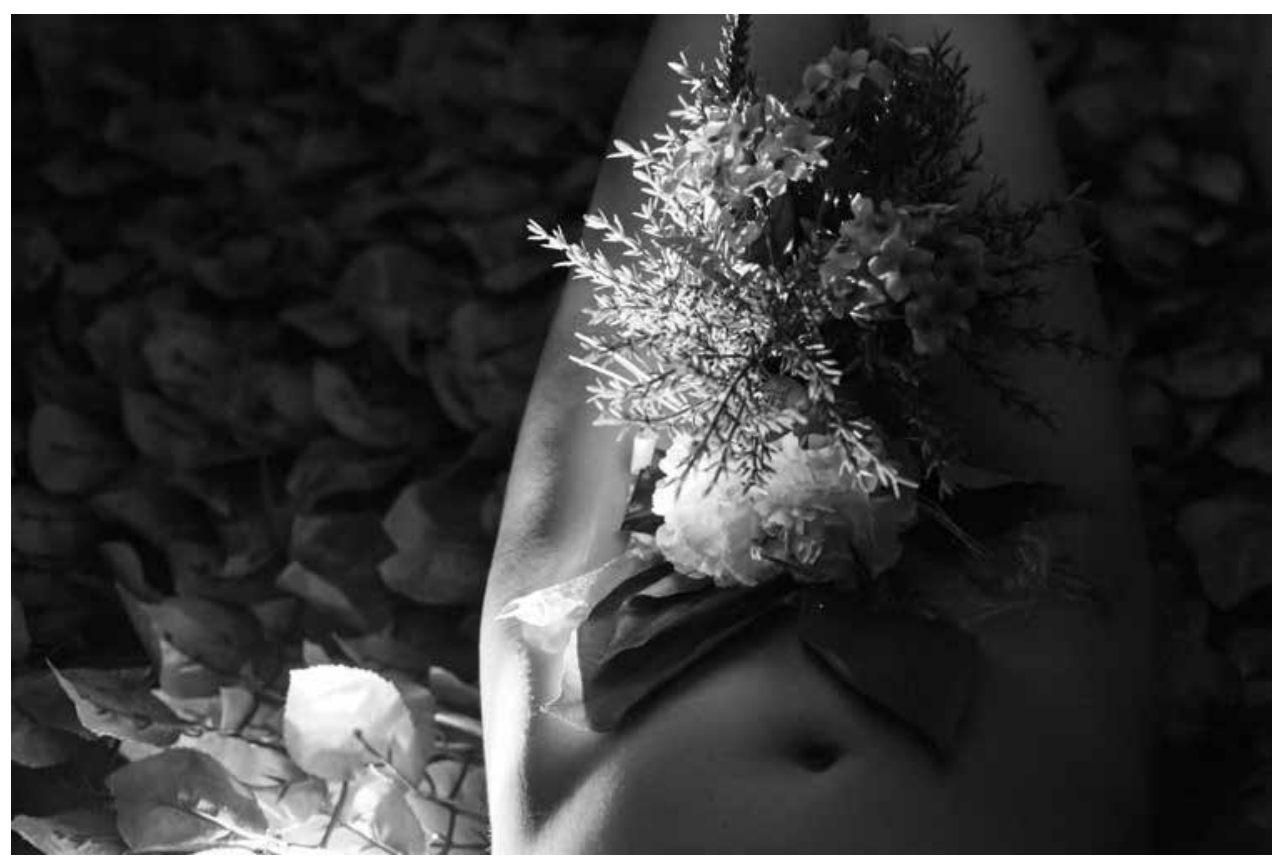

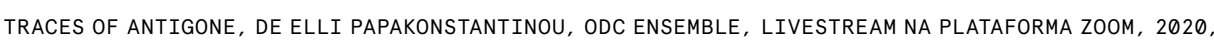
[F] SOPHIA MANOLI

começar de novo. Mais incertezas, mais perguntas, para que esta crise possa catalisar talvez o início de algo melhor-assim veremos.

Baseada na obra do mesmo título da dramaturga sueca Christina Ouzounidis, esta performance digital é uma criação da encenadora grega Elli Papakonstantinou, renomeada pela suas contribuições para um teatro político em todas as suas aceções, intrinsecamente engajado na esfera pública e preocupado em interrogar a realidade e o discurso público, através de métodos de criação transdisciplinar, de uma prática coletiva $\mathrm{e}$ numa estética disruptiva. Traces of Antigone apresenta-se como uma produção internacional multidisciplinar, que cruza recursos cinematográficos, musicais, dramatúrgicos e performativos numa exploração sem precedentes da plataforma Zoom.

Transformando simples objetos domésticos em recursos cénicos e plásticos viscerais, Traces... ataca e fala às nossas profundezas sensoriais, apesar da distância forçada pelo ecrã. Um caleidoscópio de imagens violentas e carnais sucede-se em diferentes configurações neste formato de galeria, acompanhado pelas melodias ora melancólicas e poéticas, ora ácidas e potentes, das artistas Nalyssa Green e Katerina Papachristou. Desdobrando a identidade do género feminino, interroga os seus lugares

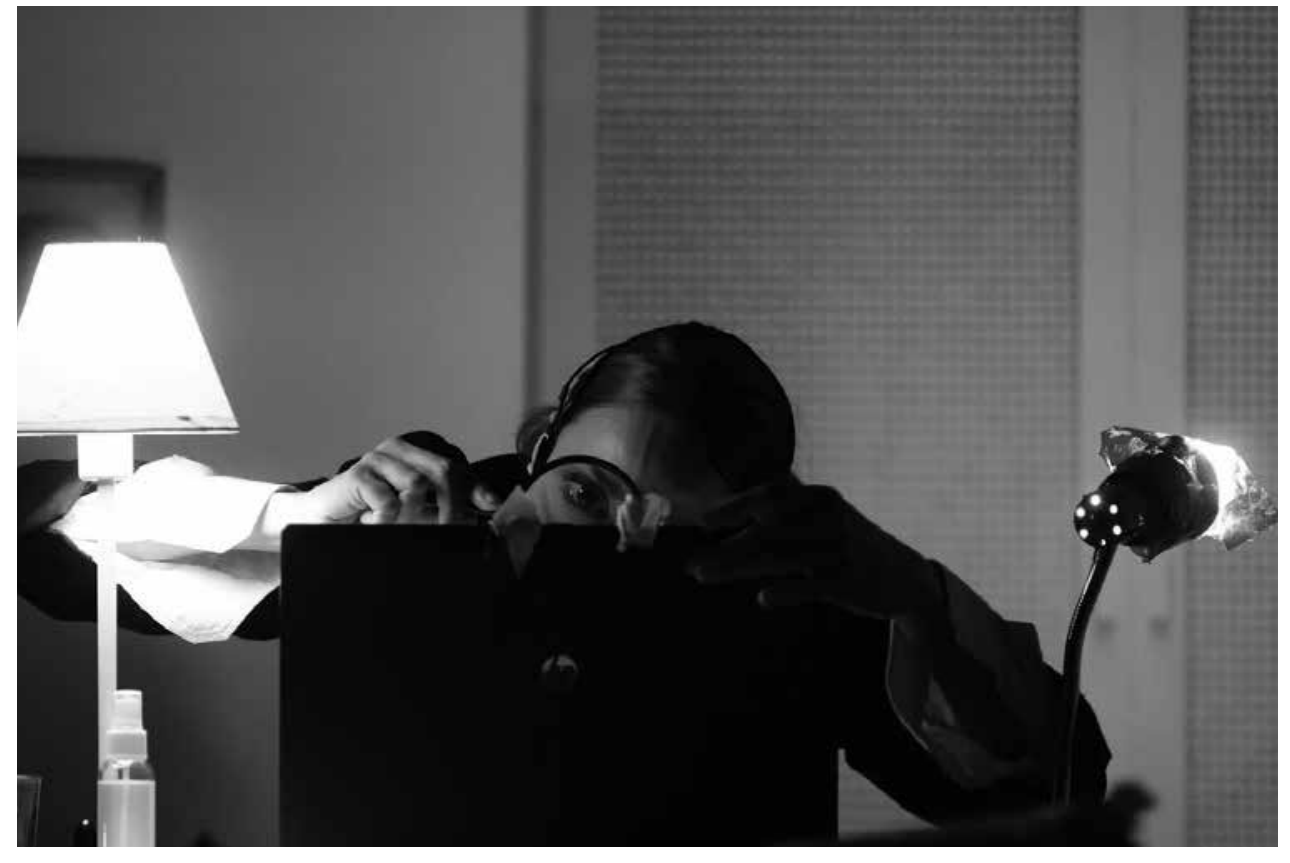

tRACES OF ANTIGONE, DE ELLI PAPAKONSTANTINOU, ODC ENSEMBLE, LIVESTREAM NA PLATAFORMA Z00M, 2020 [F] PIERO TAURO

de construção e as circunstâncias culturais que os rodeiam, as imposições e as opressões, desconstruindo a genealogia patriarcal que vem determinando a comoditização da mulher. Nos vários espaços cénicos, materializa esta constante fragmentação, refração e reflexão da figura feminina: espelhos, ecrãs, quadros, estatuária, fotografias. A experiência destas artistas reclama as fronteiras dos quadros digitais para refletir sobre o lugar da mulher como objeto do olhar, convoca as experiências transversais do ser mulher no mundo em que vivemos, utilizando um espaço predominantemente votado ao voyerismo para recuperar a sua agência e tomar as rédeas de um discurso que sistematicamente vota à opressão e violência aqueles que ousam questionar as certezas estabelecidas.

Tudo é posto em causa: tudo o que pensamos e escrevemos sobre teatro até ao presente é posto em perspetiva face a uma criação experimental síncrona como a de Papakonstantinou, que é, no entanto, múltipla nos seus espaços e temporalidades. $\mathrm{O}$ aqui e o agora dividem-se e multiplicam-se, originando uma tapeçaria de espaços privados e íntimos catapultados para um espaço público digital, interconectando e sobrepondo diferentes fusos horários. Resgatando digitalmente a experiência já longínqua de uma ida ao teatro, a hora e o ponto de encontro 


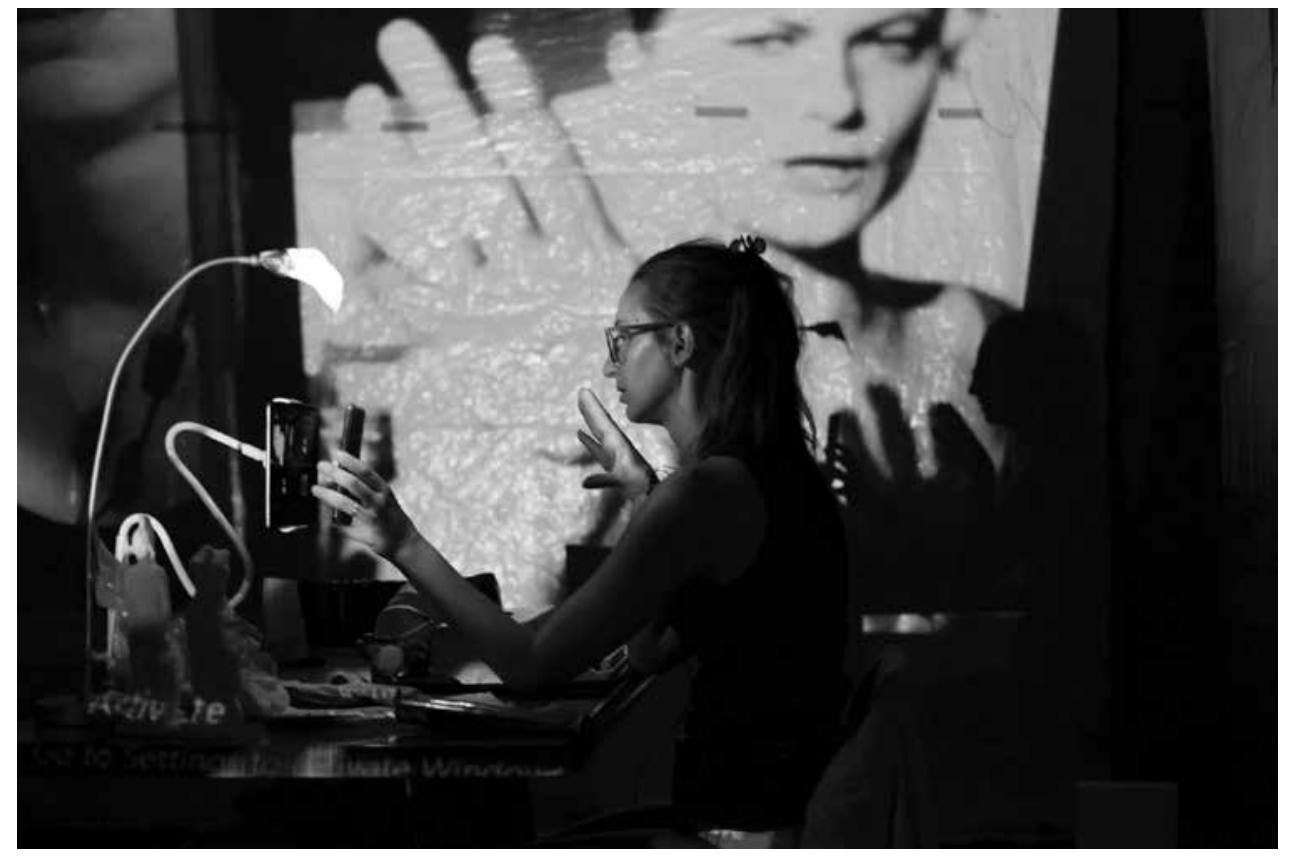

TRACES OF ANTIGONE, DE ELLI PAPAKONSTANTINOU, OdC ENSEMBLE, LIVESTREAM NA PLATAFORMA ZOOM, 2020, [F] SOPHIA MANOLI

são estabelecidos nos bilhetes adquiridos, e formalizados em convites para sessões de Zoom. Onde anteriormente percorríamos as ruas da cidade, agora percorremos as caixas de correio eletrónico. Aguardamos no foyer digital, retomam-se ligações, cumprimentam-se amigos, distribuem-se instruções para uma melhor experiência do espetáculo. O público dá lugar aos artistas, desligam-se câmaras e microfones onde antes cortinas subiriam e se escureceriam plateias. O cenário: seis casas de seis mulheres distintas em diferentes localizações geográficas encapsuladas nas fronteiras da janela digital da plataforma em que se apresentam; mas também as casas de cada espetador que a esta performance assiste, convergindo para uma ágora digital e efémera na qual todos participamos. Este dispositivo põe em questão a forma como podemos pensar o espaço público, o encontro que decorre nas artes performativas, as comunidades efémeras formadas num espaço internacional, multicultural e fragmentário por natureza. Assente na consciência de que ingressa por territórios até aqui largamente inexplorados, expondo-se à instabilidade das conexões de internet e uma miríade de outras falências técnicas, acolhe esta falibilidade nesta experiência hic et nunc, que paradoxalmente não o é em simultâneo. Podemos observar assim, num conjunto

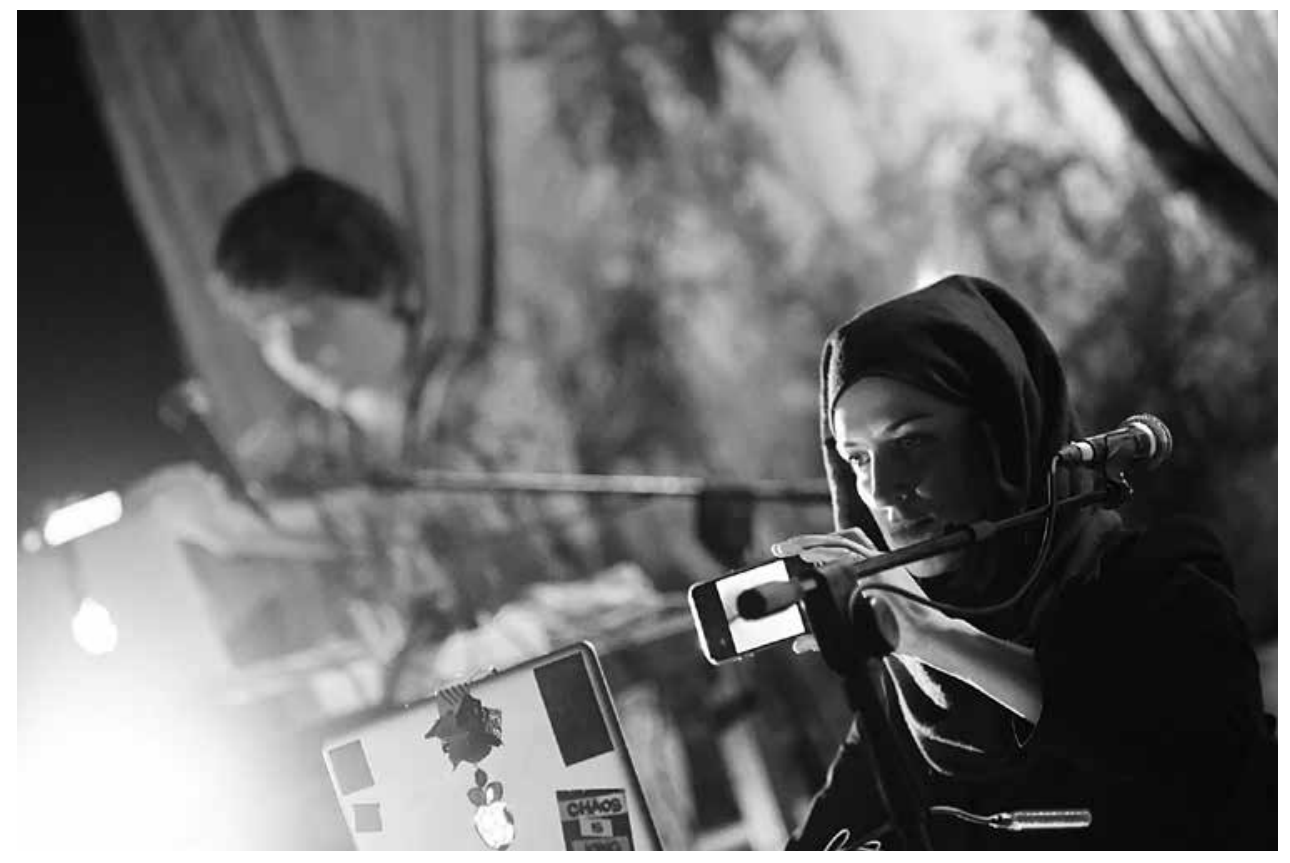

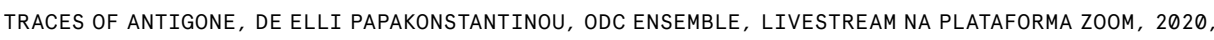
[F] PIERO TAURO

de linhas soltas e forçosamente incompletas, o pantanoso terreno de reflexão teatral que o futuro nos guarda.

Partimos numa busca inevitável sugerida pelo título, pelos traços do mito e pela rapariga perdida, procuramos Antígona na narrativa refratada e agenciada pelas seis mulheres que compõem o elenco, tentamos encontrar o seu rasto e o seu conflito multiplicado nas experiências de tantas raparigas que lhe sucederam, que resistiram. Encontrar a resistência solitária e trágica de Antígona, a sua inquebrantável vontade e a consciência premonitória do seu destino, repetida eternamente na história e cristalizada no discurso público, é um ponto de partida para a reflexão sobre o futuro da agência política, sobre os modos de resistência ainda disponíveis.

Qual o legado de Antígona? Um legado de resistência, de sofrimento? De uma vida perdida pela ousadia de contrariar a vontade coletiva, o Estado? Perguntas essenciais para compreender o lugar que ocupa esta rapariga perdida no projeto de mundo que Papakonstantinou e a sua ODC Ensemble nos propõem. Para que possa surgir terreno novo e fértil, encontramos neste legado três pilares de interrogação: a figura feminina, a linguagem e o poder. 
1. Numa interrogação mordaz ao caráter performativo do género, volvidos trinta anos desde a publicação da emblemática obra de Judith Butler (Gender Trouble: Feminism and the Subversion of Identity, 1990), olhamos a figura feminina como produto da linguagem e repetição: uma mordaça que sufoca, que vota infâncias despreocupadas ao medo, que põe a rapariga, a mulher, na vida assim que entra no mundo, sem que lhe seja garantida a oportunidade de viver como um ser humano - que a vota ao silêncio e à violência nas mãos de todas as certezas inquestionáveis.

2. Procuramos respostas para as nossas perguntas, ou devemos procurar perguntas para estas respostas que sempre tivemos? Vamos descobrir as incertezas onde certezas vivem sem questão, sem que uma voz dissidente as veja pelo que são - egos inflamados, incapazes de ouvir? Polinices morto é uma mulher, dizem-nos. Numa frase apenas, lança-se um território de questionamento renovado, que nos força a desfazer esta afirmação e os fios entrançados de uma herança do poder patriarcal: o lugar da performatividade feminina como herança de oposição às forças estabelecidas e de violência consequente que cruza transversalmente a história. Polinices, como Antígona, opôs-se ao credo da pólis, da maioria.

3. E chegamos ao centro da problemática, a dialética no cerne de Antígona: qual o lugar do indivíduo face ao coletivo? Face a um poder político corrupto, centrado nas crenças individuais e esquecido da sua obrigação de serviço ao coletivo, onde deve entrar a voz do indivíduo? Pensará o indivíduo no poder alguma vez no coletivo, ou servirá interesses pessoais? O Homem é uma doença, dizem-nos. Quem é este homem, e porque surge como uma doença? Que doença é esta? Vejamo-la como a que ameaça Tebas, os cães raivosos e as aves de rapina que infetaram os seus altares, resultado direto das ações de Creonte: do poder sem democracia, do poder narcísico e monolítico. Esta é a verdadeira doença que leva a vida de Antígona, que inquietantemente continua a levar vidas.

As oposições dialéticas multiplicam-se nas dicotomias que povoam o espetáculo - o choque entre a presença e ausência, o privado e o público, a conexão e a separação, o digital e o humano, o cultural e o natural. Traces... é um convite para refletirmos sobre os conflitos sociais e políticos que assombram a tragédia sofocliana, e o futuro que se aproxima, recusando as certezas vazias. Num momento em que todos os sistemas parecem entrar em falência e em que o espaço público como o conceptualizamos desapareceu, a cegueira face a esta, a insistência na normalidade, comprova-se mortal. Somos levados numa experiência imersiva

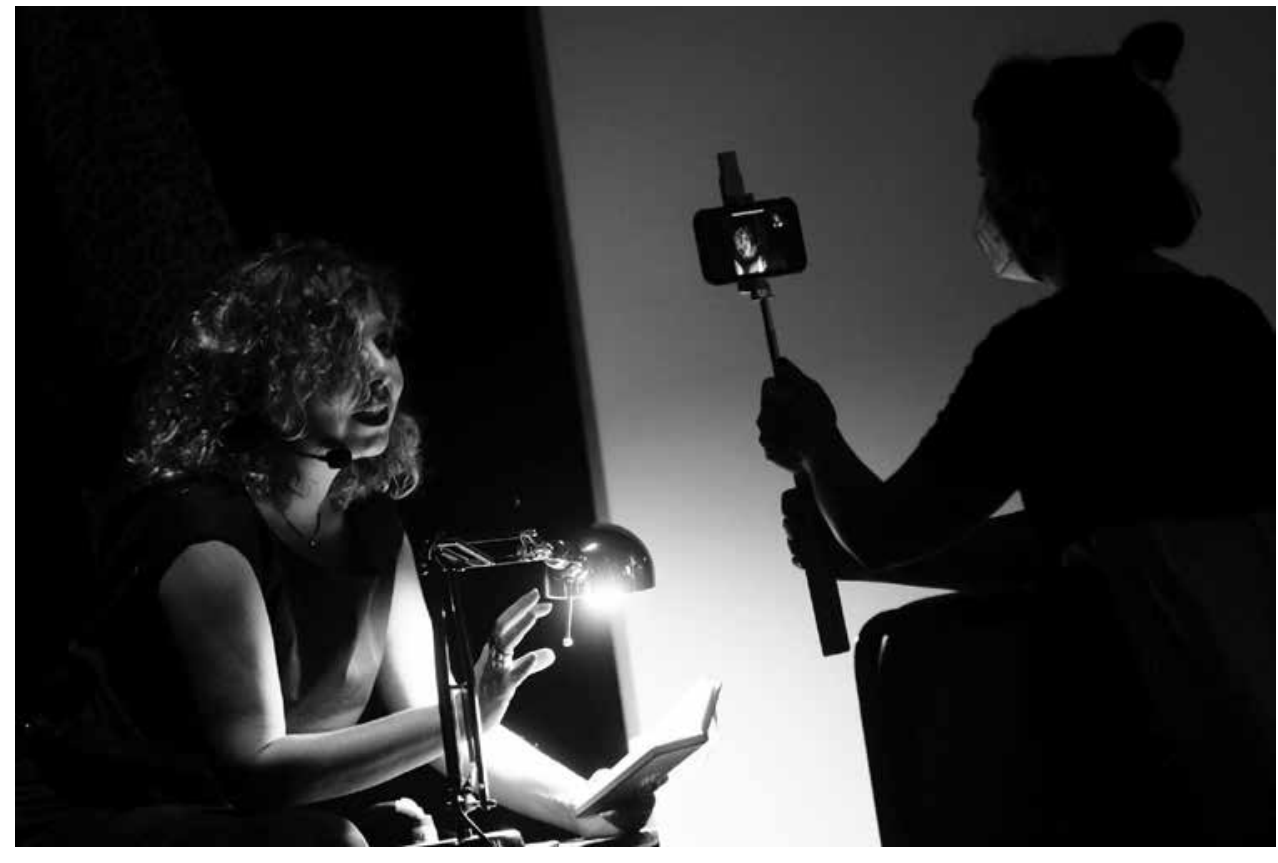

TRACES OF ANTIGONE, DE ELLI PAPAKONSTANTINOU, ODC ENSEMBLE, LIVESTREAM NA PLATAFORMA ZOOM, 2020 [F] PIERO TAURO

audiovisual e inesperada, que pretende questionar todos os domínios do mundo que habitamos e recuperar uma ágora onde possamos reunir-nos para resistir. Cada apresentação será única, abraçando a aleatoriedade possibilitada pela divisão em breakout rooms, nas quais acedemos a curtos vídeos - a sala a que acedo desaparece no eco da questão «what about ethics?».

Aproximando-nos do fim, Papakonstantinou convida os espetadores a ligar as suas câmaras e a participar da euforia de uma multidão em protesto (que parecera tão utópica e distante na era do distanciamento social, e face aos acontecimentos que se desenrolam nos EUA e um pouco por todo o mundo, parece agora premonitória da resistência que se levanta), e relembro com toda a nitidez as palavras de Florian Malzacher ao afirmar que «there is a strong desire for a theatre that not only gets a grip on pressing political issues but also becomes a public space, a public sphere, in itself» $(2015,12)$.

Afasto-me de Traces of Antigone olhando em direção a um futuro que não entrevejo ainda, segura de que as perguntas que se multiplicam são mais seguras do que a apatia. Nas mãos das certezas inabaláveis de um poder autoritário e monolítico, quantas mais vidas se perderão? Para o 
teatro, para a humanidade, como se parece o normal a que tanto insistimos retornar? No que daqui para trás ficou, quanto era realmente normal? Queremos realmente retornar a esse lugar, esquecer o que existia de errado, ou vamos repensar e resistir? Poderemos olhar esta crise como um ponto de partida para algo novo, rejeitando as certezas conformadas com a realidade que nos é apresentada, desfazendo a retórica dominante agora exposta nas suas várias falências e abraçando as incertezas como um espaço de resistência, como um local de diálogo e discussão de novas possibilidades para a humanidade?

\section{REFERÊNCIAS BIBLIOGRÁFICAS}

BUTLER, Judith (1990), Gender Trouble: Feminism and the Subversion of Identity, Nova Iorque, Routledge [trad. port.: Problemas de género - feminismo e subversão da identidade, Lisboa, Orfeu Negro, 2017].

MALZACHER, Florian (2015), «Introduction» in Florian Malzacher (ed.), Not Just a Mirror: Looking for the Political Theatre of Today, Berlim, Alexander Verlag, pp. 11-14.

Sóf OClES (2011), Antígona, trad. Marta Várzeas, Porto, TNSJ. 